\title{
SUPLEMENTOS MÚLTIPLOS DEAUTO CONTROLE DE CONSUMO NA RECRIA DE NOVILHOS NO PERÍODO DAS ÁGUAS ${ }^{1}$
}

\author{
Multiple supplements of self controlled intake for steers during the growing phase in the rainy season \\ Joanis Tilemahos Zervoudakis ${ }^{2}$, Mário Fonseca Paulino ${ }^{3}$, Luciano da Silva Cabral ${ }^{4}$, Edenio Detmann ${ }^{5}$, \\ Sebastião de Campos Valadares Filho ${ }^{5}$, Eduardo Henrique Bevitori Kling de Moraes ${ }^{6}$
}

\begin{abstract}
RESUMO
Avaliou-se o uso de suplementos de autocontrole de consumo sobre o desempenho de 24 novilhos mestiços com idade e pesos médios iniciais de 12 meses e $172 \mathrm{~kg}$, respectivamente, recriados em pastagem de Brachiaria decumbens Stapf. durante o período das águas, com disponibilidade média de 10,82 ton./ha. Forneceu-se sal mineral (SAL) e suplementos à base de: uréia, mistura mineral, milho grão triturado e farelo de soja (MFS); uréia, mistura mineral, farelo de soja e farelo de glúten de milho (FGFS); e, uréia, mistura mineral, farelo de trigo e farelo de soja (FTFS), com teor protéico médio de 53,60\% de PB. Não se verificou efeito da suplementação sobre os ganhos médios diários (P>0,05), que foram de: 0,820; 0,950; 1,020 e 0,970 kg/animal/dia, respectivamente, para SAL, MFS, FGFS e FTFS. Contudo, foram obtidos ganhos adicionais em torno de $20 \%$, os quais são de grande relevância na intensificação da pecuária de ciclo curto em pastagens.
\end{abstract}

Termos para indexação: Brachiaria decumbens, bovinos em crescimento, desempenho, proteína.

\begin{abstract}
Twenty four crossbred steers, with average initial age and weight of 12 months and $172 \mathrm{~kg}$, respectively, grazing Brachiaria decumbens Stapf., in the rainy season (10.82 ton. Dry matter/ha), were used in the performance assay to evaluate the effect of supplements of self feed. Mineral salt (SAL) and supplements based on: urea, mineral mix, grounded corn grain and soybean meal (MFS); urea, mineral mix, soybean meal and corn gluten meal (FGFS); and urea, mineral mix, wheat bran and soybean meal (FTFS), with average protein content of $53.60 \% \mathrm{CP}$, were fed. It was not observed effect $(\mathrm{P}>0.05)$ of supplementation on the average daily gain, of $0.820,0.950,1.020$ and $0.970 \mathrm{~kg} / \mathrm{animal} /$ day, respectively, for SAL, MFS, FGFS and FTFS. However, significant additional gains $(20 \%)$ were observed for supplemented steers.
\end{abstract}

Index terms: Brachiaria decumbens, beef steers in growing, performance, protein.

(Recebido em 5 de setembro de 2006 e aprovado em 22 de abril de 2008)

\section{INTRODUÇÃO}

Tendência observada mundialmente, o controle e a diminuição no consumo de gorduras pelos consumidores é uma realidade que não pode ser desprezada na pecuária nacional. Nesse sentido, a extensão territorial e de pastagens e a terminação de gado recebendo forragens verdes favorecem a produção e terminação de bovinos, em condições de menor acúmulo de gordura corporal (LUCHIARI FILHO, 1998).

Dentre os custos envolvidos no processo de suplementação, o transporte e a distribuição diária de suplementos para bovinos em pastejo são bastante expressivos. Assim, a utilização de suplementos de autocontrole de consumo permite a regulação de ingestão de suplemento pelo próprio animal, facilitando, dessa forma, o manejo e racionalizando a utilização de mão-deobra na distribuição desses suplementos nas pastagens, a qual pode ser realizada com periodicidade semanal ou mesmo quinzenal. Dessa forma, na formulação desses suplementos para recria de bovinos, são utilizados controladores de consumo, como o sal e a uréia (PAULINO et al., 2001).

\footnotetext{
${ }_{1}^{1}$ Parte da tese do primeiro autor, apresentada à Univ. Fed. de Viçosa, para obtenção do título de Doctor Scientiae em Zootecnia

2Zootecnista, Doutor, em Nutrição e Produção de Ruminantes, Professor - Departamento de Ciências Básicas e Produção Animal/DCBPA - Faculdade de Agronomia e Medicina Veterinária/FAMEV - Universidade Federal do Mato Grosso/UFMT - Avenida Fernando Correa da Costa, s/n - Coxipó - 78060 -900 Cuiabá, MT - joanis@ufmt.br

${ }^{3}$ Engenheiro Agrônomo, Doutor em Nutrição e Produção de Ruminantes, Professor, Pesquisador - Departamento de Zootecnia/DZO - Universidade Federal de Viçosa/UFV - Avenida PH Rolfs, s/n - Centro - 36570-000 - Viçosa, MG - mpaulino@ufv.br

${ }^{4}$ Zootecnista, Doutor, Professor- Departamento de Zootecnia/DZO - Universidade Federal de Viçosa/UFV - Avenida PH Rolfs, s/n - Centro - $36570-000$ Viçosa, MG - cabralls@ufmt.brr

${ }^{5}$ Zootecnistas, Doutores - Departamento de Zootecnia/DZO - Universidade Federal de Viçosa/UFV - Avenida PH Rolfs, s/n - Centro - $36570-000$ Viçosa, MG - detmann@ufv.br; scvfilho@ufv.br

${ }^{6}$ Zootecnista, Doutor em Nutrição e Produção de Ruminantes - Departamento de Zootecnia - Instituto Universitário do Norte Matogrossense/IUNM Universidade Federal de Mato Grosso/UFMT - Avenida Alexandre Ferronato, 1200 - 78550-000 - Sinop, MT - ebbkm@ufmt.br
} 
Alimentos ricos em proteína, como os farelos de soja e de algodão são fontes amplamente utilizadas na composição de suplementos múltiplos, para bovinos em pastejo. Esses alimentos atuam de forma a estimular maior digestão ruminal da forragem, aumentando a extração de energia a partir da forragem, reduzindo o tempo de retenção da digesta ruminal e permitindo, conseqüentemente, maior consumo de forragem pelo animal (LUSBY et al., 1998).

Em estudos avaliando os efeitos de diferentes fontes e concentrações de Proteína Bruta (PB), em suplementos múltiplos de autocontrole de consumo, foi verificada pequena influência das diferentes fontes e concentrações de PB, sobre a digestibilidade dos nutrientes (DRIEDGER \& LOERCH, 1999). Entretanto, a maioria dos estudos avaliando a suplementação de bovinos com suplementos de autocontrole de consumo, têm sido conduzidos principalmente durante o período seco do ano, sendo ainda escassos os estudos visando avaliar a viabilidade da utilização de suplementos de autocontrole de consumo na recria de bovinos, durante o período das águas. Dessa forma, objetivou-se, neste estudo, avaliar a influência de suplementos de autocontrole de consumo com diferentes associações de fontes protéicas e energéticas, no desempenho de novilhos recriados a pasto, durante o período das águas.

\section{MATERIALE MÉTODOS}

O experimento foi conduzido nas dependências da Central de Experimentação, Pesquisa e Extensão do Triângulo Mineiro - CEPET/UFV, localizado no município de Capinópolis-MG, durante o período das águas entre os meses de dezembro de 2000 e fevereiro de 2001, totalizando 84 dias de ensaio de desempenho. A área experimental destinada aos animais para avaliação de desempenho foi constituída por 4 piquetes de 3 ha, cobertos uniformemente com gramínea Brachiaria decumbens Stapf., providos de bebedouros e comedouros cobertos.

Foram utilizados 24 novilhos mestiços HolandêsZebu, não-castrados, com idade e pesos médios iniciais de 12 meses e $172 \mathrm{~kg}$, respectivamente, distribuídos aleatoriamente entre os tratamentos, assim constituídos: SAL - controle, mistura mineral;

MFS - suplemento constituído de mistura mineral, uréia/ sulfato de amônio (9:1), milho grão triturado e farelo de soja;

FGFS - suplemento constituído de mistura mineral, uréia/ sulfato de amônio (9:1), farelo de glúten de milho (Promil) e farelo de soja;

FTFS - suplemento constituído de mistura mineral, uréia/ sulfato de amônio (9:1), farelo de trigo e farelo de soja.

Os animais foram pesados ao início e final do experimento após serem submetidos a jejum de sólidos e líquidos de 18 horas e a cada 28 dias foram realizadas pesagens intermediárias dos animais. Posteriormente, os animais foram rotacionados entre os piquetes, visando reduzir possíveis variações entre piquetes experimentais. Todos os animais foram submetidos ao controle de ecto e endoparasitas, no início do experimento.

A composição porcentual dos suplementos encontra-se na Tabela 1. Os suplementos foram fornecidos ad libitum, diariamente às 10:00 h, monitorando-se as quantidades fornecidas e as possíveis sobras de suplementos.

Tabela 1 - Composição percentual dos suplementos, com base na matéria natural.

\begin{tabular}{|c|c|c|c|c|}
\hline \multirow[b]{2}{*}{ Itens } & \multicolumn{4}{|c|}{ Tratamentos } \\
\hline & SAL & MFS & FGFS & FTFS \\
\hline & \multicolumn{4}{|c|}{ Proporção dos Ingredientes (\%) } \\
\hline Mistura Mineral $^{1}$ & 100,0 & 10 & 10 & 10 \\
\hline Uréia/Sulfato de Amônio (9:1) & --- & 10 & 10 & 10 \\
\hline Farelo de Soja & --- & 50 & 30 & 40 \\
\hline Milho Grão Triturado & --- & 30 & --- & --- \\
\hline Farelo de Glúten de Milho ${ }^{2}$ & --- & --- & 50 & --- \\
\hline Farelo de Trigo & --- & --- & --- & 40 \\
\hline
\end{tabular}

${ }^{1}$ Composição porcentual: fosfato bicálcico, 48,61; cloreto de sódio, 48,61; sulfato de zinco, 1,46; sulfato de cobre, 0,72 ; sulfato de magnésio, 0,50; sulfato de cobalto, 0,05 e iodato de potássio, 0,05 .

${ }^{2}$ Promil 21 - CARGIL nutrição animal. 
No primeiro dia de permanência em cada piquete foi realizada a coleta de pastagem para determinação da disponibilidade total de matéria seca/ha, através do corte rente ao solo, em cinco áreas delimitadas por um quadrado metálico de $0,5 \times 0,5 \mathrm{~m}$, escolhidas aleatoriamente em cada piquete.

A avaliação da dieta ingerida pelos animais foi realizada utilizando a extrusa esofágica, coletada por quatro bovinos canulados no esôfago e mantidos em área anexa, coberta uniformente com Brachiaria decumbens Stapf.. As amostras de extrusa foram coletadas às 7:00 h nos dias 5 e 21 de cada período intermediário às pesagens, com auxílio de bolsas coletoras com fundo telado, após os animais serem submetidos a um jejum prévio de 12 horas, segundo recomendações de Minson et al. (1976). As amostras foram posteriormente compostas em amostra única, por animal/período.

Todo o material coletado foi imediatamente congelado em freezer a $-20^{\circ} \mathrm{C}$ para posteriormente ser analisado no Laboratório de Nutrição Animal do Departamento de Zootecnia da Universidade Federal de Viçosa em ViçosaMG. As amostras após serem secas e moídas foram submetidas às análises de: matéria seca (MS), matéria orgânica (MO), nitrogênio total (NT), extrato etéreo (EE), matéria mineral (MM) e lignina, realizadas de acordo com as técnicas descritas por Silva \& Queiroz (2002). As determinações de fibra em detergente neutro (FDN) e fibra em detergente ácido (FDA) seguiram o método de extração de micro - FDN por intermédio de autoclavagem da amostra (PELL \& SHOFIELD, 1993), com devidas correções de procedimento para a presença de amido, proteínas e cinzas (SOEST et al., 1991).

Os carboidratos não fibrosos (CNF) dos suplementos foram estimados de acordo com Hall (2000), utilizando desconto para porcentagem de PB oriunda de fontes de nitrogênio não protéico (NNP). O teor de nutrientes digestíveis totais (NDT OBS) das dietas, e o teor de NDT estimado (NDT EST) foi calculado por intermédio da equação proposta pelo NRC (2001) e segundo valores propostos por Valadares Filho et al. (2002).

As análises referentes ao desempenho dos animais experimentais foram conduzidas em um delineamento inteiramente casualizado, segundo o modelo:

$$
\mathrm{y}_{\mathrm{ij}}=\mu+\mathrm{t}_{\mathrm{i}}+\mathrm{e}_{\mathrm{ij},}
$$

em que:

$\mu=$ constante geral;

$\mathrm{t}_{\mathrm{i}}=$ efeito do suplemento $\mathrm{i}$, sendo $\mathrm{i}=1,2,3$ e 4;

$\mathrm{e}_{\mathrm{ij}}=$ erro aleatório, associado a cada observação, pressuposto NID $\left(0, \sigma^{2}\right)$.
Para comparações entre médias, adotou-se o teste de Newman Keulls, sendo que todas as análises foram realizadas por intermédio do programa Saeg - UFV (1995), adotando-se o nível de significância de 5\%.

\section{RESULTADOS E DISCUSSÃO}

A disponibilidade média de matéria seca nas forragens, durante a condução do presente estudo é apresentada na Figura 1. Foram observados valores médios de disponibilidade de matéria seca de $10.385 \mathrm{~kg} / \mathrm{ha}$, os quais propiciaram condições adequadas para que os animais exercessem o pastejo seletivo.

A composição bromatológica da extrusa e dos suplementos é apresentada na Tabela 2. Foram observados valores médios de $10,82 \%$ de PB da extrusa, sendo esse valor superior aos valores obtidos por Detmann et al. (2001) e Zervoudakis et al. (2001), que analisando amostras de extrusa no período chuvoso, obtiveram médias de 9,9 e 8,8\% PB, respectivamente; e inferiores aos obtidos por Paulino et al. (2002), que encontraram valores médios de $11,71 \%$ PB para Brachiaria decumbens Stapf., durante o período das águas, via simulação do pastejo animal.

Os valores referentes à FDN das amostras de extrusa $(66,62 \%)$ foram inferiores aos relatados por Detmann et al. (2001), 71,72\% FDN, e próximos aos valores observados por Paulino et al. (2002), que encontraram FDN média de 66,22\% em amostras de Brachiaria decumbens Stapf., obtidas via simulação do pastejo animal.

Em virtude da elevada disponibilidade de matéria seca durante o experimento, os animais selecionaram forragem de boa composição bromatológica (Tabela 2), que propiciou adequado aporte de nutrientes, conforme pode ser visualizado na Tabela 3 , mediante análise do desempenho dos animais controle (SAL), que apresentaram ganhos médios diários em torno de $820 \mathrm{~g}$.

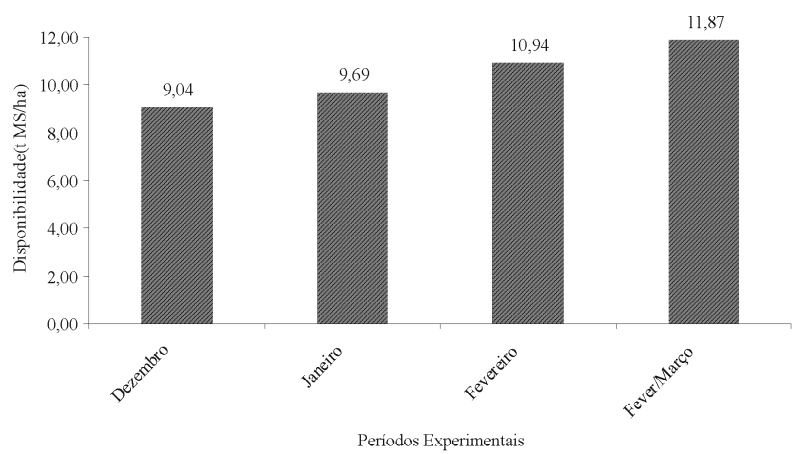

Figura 1 - Disponibilidade total de matéria seca para a pastagem, durante o experimento. 
Tabela 2 - Composição bromatológica da extrusa esofágica (Brachiaria decumbens) e dos suplementos, com base na matéria seca.

\begin{tabular}{|c|c|c|c|c|c|}
\hline \multirow[b]{2}{*}{ Itens $^{1}$} & \multirow[b]{2}{*}{ Extrusa } & \multicolumn{4}{|c|}{ Suplementos } \\
\hline & & SAL & MFS & FGFS & FTFS \\
\hline MS (\%) & 13,17 & --- & 90,93 & 90,38 & 91,29 \\
\hline Cinzas $^{2}$ & 10,63 & --- & 3,69 & 4,61 & 4,37 \\
\hline $\mathrm{MO}^{2}$ & 89,37 & --- & 96,31 & 95,39 & 95,63 \\
\hline $\mathrm{PB}^{2}$ & 10,82 & --- & 54,16 & 53,86 & 52,84 \\
\hline $\mathrm{NIDN}^{3}$ & 6,54 & --- & 5,39 & 8,74 & 6,13 \\
\hline NIDA $^{3}$ & 5,37 & --- & 3,27 & 2,78 & 2,35 \\
\hline $\mathrm{EE}^{2}$ & 0,59 & --- & 3,00 & 2,19 & 2,38 \\
\hline $\mathrm{CT}^{2,4}$ & 77,96 & --- & 54,35 & 54,54 & 55,61 \\
\hline $\mathrm{FDN}^{2}$ & 66,62 & --- & 10,42 & 23,07 & 20,87 \\
\hline $\mathrm{CNF}^{2}$ & 11,34 & --- & 43,93 & 31,47 & 34,74 \\
\hline $\mathrm{FDA}^{2}$ & 29,05 & --- & 6,33 & 8,15 & 7,43 \\
\hline Lignina $^{2}$ & 3,09 & --- & 0,55 & 0,95 & 1,01 \\
\hline $\mathrm{FDAi}^{2}$ & 12,64 & --- & 0,57 & 2,27 & 2,29 \\
\hline $\operatorname{NDT}(\%)^{5}$ & --- & --- & 66,21 & 61,03 & 61,50 \\
\hline
\end{tabular}

${ }^{1 /}$ MS - matéria seca; MO - matéria orgânica; PB - proteína bruta; NIDN - nitrogênio indigerível em detergente neutro; NIDA nitrogênio indigerível em detergente ácido; $\mathrm{EE}$ - extrato etéreo;

$\mathrm{CT}$ - carboidratos totais; FDN - fibra em detergente neutro; CNF - carboidratos não fibrosos;

FDA - fibra em detergente ácido; FDAi - fibra em detergente ácido indigestível;

${ }^{2 /} \%$ MS. ${ }^{3 /} \%$ dos compostos nitrogenados totais. ${ }^{4 /} \mathrm{CT}=$ FDNcp + CNF.

${ }^{5 /} \mathrm{NDT}$ - nutrientes digestíveis totais - Estimado segundo valores propostos por

Valadares Filho et al. (2002).

Tabela 3 - Valores médios de peso corporal inicial (PC Inicial) e final (PC final), ganhos de peso total (GDP Total) e médio diário (GMD, g/dia) e consumo de suplemento (g/dia) para os animais experimentais.

\begin{tabular}{lcccc}
\hline \multirow{2}{*}{ Itens } & \multicolumn{4}{c}{ Tratamentos } \\
\cline { 2 - 5 } & SAL & MFS & FGFS & FTFS \\
\hline PC Inicial (kg) & 162,2 & 177,5 & 176,8 & 171,5 \\
PC Final (kg) & 230,7 & 257,3 & 262,2 & 253,0 \\
GDP Total (kg) & 68,5 & 79,8 & 85,4 & 81,5 \\
GMD $^{1}$ & 820 & 950 & 1020 & 970 \\
Consumo Suplemento & 52 & 693 & 690 & 658 \\
\hline
\end{tabular}

${ }^{1 / E f e i t o ~ r e l a t i v o ~ a ~ t r a t a m e n t o ~ n a ̃ o ~ s i g n i f i c a t i v o ~ p e l o ~ t e s t e ~} \mathrm{~F}(\mathrm{P}>0,05)$.

Verifica-se que os níveis de $10 \%$ de mistura mineral e $10 \%$ de uréia na composição dos suplementos, foram efetivos em controlar o consumo, em torno de $680 \mathrm{~g} / \mathrm{animal} /$ dia (0,4\% Peso Corporal - PC), situado entre os valores de 0,4-0,5\% PC, preconizados por Paulino et al. (2001) para recria de novilhos superprecoces em pastejo.

Os resultados encontrados para ganho médio diário dos animais submetidos somente à suplementação com mistura mineral (SAL) foram próximos aos obtidos por Zervoudakis et al. (2001), os quais encontraram ganhos médios de $890 \mathrm{~g} / \mathrm{dia}$, durante o período das águas, em pastagens de $B$. decumbens, com alta disponibilidade de MS/ha (6.736 kg MS/ha).

Os suplementos MFS, FGFS e FTFS atenderam aos requisitos de NDT e de $\mathrm{PB}$ em torno de 11,78; 11,61 e 11,11\%; e 46,$93 ; 49,91$ e $46,49 \%$, respectivamente, estimados 
segundo o NRC (1996), para um animal de $200 \mathrm{~kg}$ e com ganho médio de $1 \mathrm{~kg} /$ dia. Embora não tenham sido verificadas diferenças significativas no desempenho dos animais suplementados, quando comparados aos animais controle (SAL), constata-se que os animais suplementados apresentaram, em média, desempenho $20 \%$ superior aos animais suplementados apenas com mistura mineral (SAL).

Neste sentido, o fornecimento de fontes protéicas com diferentes degradabilidades ruminais (FGFS) propiciou ganhos adicionais (numericamente superiores), em torno de $200 \mathrm{~g} /$ dia superior ao dos animais do tratamento controle (SAL). Apesar da menor magnitude dos ganhos obtidos com a suplementação no período das águas quando comparados à suplementação durante o período seco do ano, enfoque diferenciado deve ser dado à suplementação nesse período, tendo em vista que fatores como precocidade produtiva e reprodutiva, menor tempo de permanência dos animais nos pastos e maior giro de capital devem ser avaliados dentro do sistema produtivo como um todo, na busca de maior intensificação da pecuária de ciclo curto.

Resultados semelhantes ao do presente estudo foram encontrados por Marcondes et al. (2002) que, objetivando avaliar o desempenho de animais recriados em pastagens de $B$. decumbens durante o período das águas, utilizaram suplementos múltiplos energéticos ou protéicos com diferentes degradabilidades ruminais, encontrando desempenhos superiores dos animais suplementados com Proteína Degradada no Rúmen (PDR) e Proteína Não Degradada no Rúmen (PNDR), em relação aos animais submetidos à suplementação energética (milho) e mineral. De acordo com esses autores, os ganhos adicionais obtidos com a suplementação protéica seriam influenciados, em maior escala, pelo fornecimento de proteína metabolizável do que pela energia fornecida pelos suplementos, sendo que os suplementos contendo PNDR e fornecidos em quantidades diárias de $1 \mathrm{~kg}(0,5 \% \mathrm{PC})$ foram mais efetivos no fornecimento de proteína metabolizável, para os animais do que os suplementos contendo PDR.

Neste sentido, Poppi \& Mclennan (1995) ressaltaram que, durante o período das águas, as gramíneas forrageiras não apresentam deficiência de $\mathrm{PB}$, contudo, a alta degradabilidade da PB da gramínea forrageira induz a transferências incompletas da proteína da forragem para os intestinos, o que provoca perdas excessivas de compostos nitrogenados na forma de amônia. Adicionalmente, Detmann et al. (2004) destacou que, embora durante os períodos seco e chuvoso do ano as deficiências nutricionais estejam relacionadas à proteína, a mudança do período seco para o período chuvoso altera o enfoque dado a essa deficiência, transformando-a de dietética em metabólica.

No presente estudo, os suplementos: MFS; FGFS e FTFS apresentaram-se em torno de 46,32; 46,74 e 44,86\% PDR e 7,84; 7,12 e 7,98\% PNDR, respectivamente. Adicionalmente, foram observados consumos de PDR e PNDR para as dietas contendo os suplementos MFS, FGFS e FTFS de 250; 250 e 230 g/dia e 60; 60 e 60 g/dia, respectivamente, estimados segundo valores do NRC (2001), considerando-se uma taxa de passagem de $0,05 \mathrm{~h}^{-1}$.

\section{CONCLUSÕES}

O fornecimento de suplementos de autocontrole de consumo não influenciou o desempenho de novilhos recriados no período das águas, em pastagens de Brachiaria decumbens com alta qualidade, contudo, foram obtidos numericamente, ganhos adicionais em torno de $20 \%$, que são de grande relevância na intensificação da pecuária de ciclo curto em pastagens.

\section{REFERÊNCIAS BIBLIOGRÁFICAS}

DETMANN, E.; PAULINO, M. F.; ZERVOUDAKIS, J. T. Suplementação de novilhos mestiços durante a época das águas: parâmetros ingestivos e digestivos. Revista Brasileira de Zootecnia, Viçosa, v. 30, n. 4, p. 1340-1349, 2001.

DETMANN, E.; PAULINO, M. F.; ZERVOUDAKIS, J. T. Níveis de proteína bruta em suplementos múltiplos para terminação de novilhos mestiços em pastejo durante a época seca: desempenho produtivo e características de carcaça. Revista Brasileira de Zootecnia, Viçosa, v. 33, n. 1, p. 169-180, 2004.

DRIEDGER, L. J.; LOERCH, S. C. Effects of protein concentration and source on nutrient digestibility by mature steers limit-Fed high-concentrate diets. Journal of Animal Science, Champaign, v. 77, p. 960-966, 1999.

HALL, M. B. Calculation of non-strucutural carbohydrate content of feeds that contain no-protein nitrogen. Florida: University of Florida, 2000. (Bulletin 339).

LUCHIARI FILHO, A. Perspectivas da pecuária de corte brasileira. In: SIMPÓSIO SOBRE PRODUÇÃO INTENSIVA DE GADO DE CORTE, 1998, Campinas, SP. Anais... Campinas: Unicamp, 1998. p. 1-10.

LUSBY, K.; STEVENS, V.; APPLE, K. Supplementing the cow herd. Oklahoma: Cooperative Extension Service, 1998. Disponível em: <http://Www.ansi.okstate.edu/exten/beef $>$. Acesso em: 10 out. 2007 . 
MARCONDES, P. C. F.; ALVES, J. B.; ISEPON, O. J. Desempenho de bovinos em pastagens de Brachiaria decumbens suplementados com proteína e energia no período das águas. In: REUNIÃO ANUAL DA SOCIEDADE BRASILEIRA DE ZOOTECNIA, 39., 2002, Recife. Anais... Recife: Sociedade Brasileira de Zootecnia, 2002. CD-ROM.

MINSON, D. J.; STOBBS, T. H.; HEGARTY, M. P. Measuring the nutritive value of pasture plants. In: SHAW, N. H.; BRYAN, W. W. (Eds.). Tropical pasture research. Oxford: CAB International, 1976. p. 308-333.

NATIONAL RESEARCH COUNCIL. Nutrient requirements of beef cattle. 7. ed. Washington, DC, 1996. 243 p.

NATIONAL RESEARCH COUNCIL. Nutrients requirements of dairy cattle. 7. ed. Washington, DC: National Academy, 2001.381 p.

PAULINO, M. F.; DETMANN, E.; ZERVOUDAKIS, J. T. Suplementos múltiplos para recria e engorda de bovinos em pastejo. In: SIMPÓSIO DE PRODUÇÃO DE GADO DE CORTE, 2., 2001, Viçosa, MG. Anais... Viçosa: UFV, 2001. p. 187-231.

PAULINO, M. F.; MORAES, E. H. K. B. de; ZERVOUDAKIS, J. T. Suplementação de novilhos mestiços recriados em pastagens de Brachiaria decumbens durante o período das águas: desempenho. In:REUNIÃO ANUAL DA SOCIEDADE BRASILEIRA DE ZOOTECNIA, 39., 2002, Recife. Anais... Recife: Sociedade Brasileira de Zootecnia, 2002. CD-ROM.
PELL, A. N.; SCHOFIELD, P. Computerized monitoring of gas production to measure forage digestion in vitro. Journal of Dairy Science, Champaign, v. 76, n. 4, p. 10631073, 1993.

POPPI, D. P.; McLENNAN, S. R. Protein and energy utilization by ruminants at pasture. Journal of Animal Science, Champaign, v. 73, p. 278-290, 1995.

SILVA, D. J.; QUEIROZ, A. C. Análise de alimentos: métodos químicos e biológicos. 3. ed. Viçosa: UFV, 2002. $165 \mathrm{p}$.

SOEST, P. J. van; ROBERTSON, J. B.; LEWIS, B. A. Methods for dietary fiber, and nonstarch polysaccharides in relation to animal nutrition. Journal of Dairy Science, Champaign, v. 74, n. 10, p. 3583-3597, 1991.

UNIVERSIDADE FEDERAL DE VIÇOSA.SAEG -Sistema de Análises Estatísticas e Genética. Viçosa, 1995. Apostila.

VALADARES FILHO, S. C.; ROCHA JÚNIOR, V. R.; CAPELLE, E. R. CQBAL 2.0: tabelas brasileiras de composição de alimentos para bovinos. Viçosa: UFV, 2002. $279 \mathrm{p}$.

ZERVOUDAKIS, J. T.; PAULINO, M. F.; DETMANN, E. Desempenho e características de carcaça de novilhos suplementados no período das águas. Revista Brasileira de Zootecnia, Viçosa, v. 30, n. 4, p. 1381-1389, 2001. 